\title{
Pyridine-modulated Ni/Co bimetallic metal-organic framework nanoplates for electrocatalytic oxygen evolution
}

\author{
Yang Bai ${ }^{1}$, Guangxun Zhang ${ }^{1}$, Shasha Zheng ${ }^{1}$, Qing Li $^{1,2}$, Huan Pang ${ }^{1 *}$ and Qiang Xu ${ }^{1,3}$
}

ABSTRACT Two-dimensional (2D) metal-organic frameworks (MOFs) are promising for electrocatalysis with high performance, as they possess large surface areas and high densities of exposed active sites. It attracts tremendous attention to obtain 2D nanostructures via simple preparation methods. Herein, a facile pyridine-modulated solvothermal synthesis of $\mathrm{Ni} / \mathrm{Co}$ bimetallic MOF nanoplates $\left(\mathrm{Ni}_{x} \mathrm{Co}_{y}\right.$-bpy $(\mathrm{PyM}))$ is reported with well-defined $2 \mathrm{D}$ morphology with a thickness as thin as $\mathbf{2 0} \mathbf{~ m m}$ and an aspect ratio larger than $\mathbf{5 0}$. These nanoplates possess oxygen evolution reaction activity as electrocatalysts in alkaline conditions. Specifically, $\mathrm{Ni}_{0.5} \mathrm{Co}_{1.5^{-}}$ bpy(PyM) exhibits excellent OER electrocatalytic activity with a low overpotential of $256 \mathrm{mV}$ at $10 \mathrm{~mA} \mathrm{~cm}$ and a small Tafel slope of $81.8 \mathrm{mV} \mathrm{dec}^{-1}$ in $1.0 \mathrm{~mol} \mathrm{~L}^{-1} \mathrm{KOH}$ with long-term electrochemical stability for 3000 cyclic voltammetry cycles. The high catalytic activity of $\mathrm{Ni}_{0.5} \mathrm{Co}_{1.5}-\mathrm{bpy}(\mathrm{PyM})$ can be attributed to the in situ formed active hydroxide and oxyhydroxide species within the inherited $2 \mathrm{D}$ morphology and the optimized bimetallic ratio.

Keywords: metal-organic framework, bimetallic MOF nanoplate, electrocatalysis, oxygen evolution reaction

\section{INTRODUCTION}

Metal-organic frameworks (MOFs) are a class of crystalline and porous materials of various dimensionalities built from metal cations and organic ligands [1]. MOFs possess large surface areas, high porosities, and multiple functionalities, which render them ideal candidates for catalysis, gas storage and separation, and drug delivery [2-5]. Besides the conventional three-dimensional (3D) MOFs, the conversion of traditional bulk MOFs into 2D nanostructures with a vertical dimension of less than $100 \mathrm{~nm}$ has attracted tremendous attentions [6,7]. The 2D nanostructures are characterized by faster mass transport, lower diffusion barrier, and more exposed active sites, which allow the molecules or ions to directly access the active sites $[8,9]$. These features render them promising candidates to improve catalytic performance [10-14].

The syntheses of 2D MOF nanostructures can be realized by top-down or bottom-up methods [15]. The former refers to the exfoliation of MOFs into layered structures [16-19], while the later involves the direct synthesis from metal ions and organic ligands, such as interfacial synthesis, surfactant-assisted synthesis, and modulated synthesis [20,21]. Of the above, the modulated synthesis refers to the introduction of modulator molecules into the reaction mixture [22]. These modulator molecules possess similar functional groups in the organic linkers, and coordinate with the metal or metal clusters, thus regulating the growth kinetics of MOFs. Appropriate coordination of these molecules on certain crystal planes could inhibit the growth of MOFs, resulting in the anisotropic MOF growth. Direct modulator introduction is an effective and facile way to control the morphologies of MOFs with features of nanocubes, nanorods and nanosheets [23,24].

Electrochemical splitting of water has been considered as a promising strategy for obtaining clean and sustainable hydrogen energy source [25-27]. The oxygen evolution reaction (OER) is the critical half-cell reaction of water splitting and a rate-limiting step, which requires a high overpotential and suffers from sluggish kinetics because of the high energy barrier for the breaking-up of

\footnotetext{
${ }^{1}$ School of Chemistry and Chemical Engineering, Yangzhou University, Yangzhou 225009, China

${ }^{2}$ Guangling College, Yangzhou University, Yangzhou 225009, China

${ }^{3}$ AIST-Kyoto University Chemical Energy Materials Open Innovation Laboratory (ChEM-OIL), National Institute of Advanced Industrial Science and Technology (AIST), Kyoto 606-8501, Japan

*Corresponding author (email: huanpangchem@hotmail.com or panghuan@yzu.edu.cn)
} 
$\mathrm{O}-\mathrm{H}$ bond and the formation of $\mathrm{O}-\mathrm{O}$ bond [28]. Therefore, to effectively couple multiple protons and electron transfers for oxygen evolution at a low overpotential, efficient electrocatalysts are desired [29,30]. Although iridium (Ir) and ruthenium (Ru) oxides show efficient electrocatalytic activity, their scarcity and high cost hinder extensive industrial applications [31]. Recently, significant efforts have been devoted to developing OER electrocatalysts that possess fast reaction rate, small overpotential and stability [32-36].

MOFs offer a great potential as OER electrocatalysts because of their tunable surface atomic structures and coordinatively unsaturated metal sites with high catalytic activity [32]. In addition, the open channels and accessible pores could facilitate the diffusion of electrolytes and the evolution/transport of $\mathrm{O}_{2}$. The $2 \mathrm{D}$ MOFs could act as effective catalysts for OER electrocatalysis, because their nanometer thicknesses facilitate rapid mass and electron transport and the 2D structure provides a high percentage of exposed catalytic active surfaces [29,37]. Zhao et al. [18] reported $\mathrm{Ni} / \mathrm{Co}$ bimetallic MOF nanosheets (NiCoUMOFNs) with a uniform thickness of approximately $3.1 \mathrm{~nm}$ through exfoliation. The NiCo-UMOFNs exhibited high OER electrocatalytic activity with an overpotential of $250 \mathrm{mV}$ when loaded on glassy-carbon electrodes, and $189 \mathrm{mV}$ when loaded on copper foam at $10 \mathrm{~mA} \mathrm{~cm}^{-2}$ in alkaline conditions. Duan et al. [37] reported a strategy for the in situ growth of ultrathin nanosheet arrays of 2D MOFs on various supports via chemical bath deposition. In this way, a Ni/Fe MOF array was fabricated which demonstrated OER electrocatalytic activity with an overpotential of $240 \mathrm{mV}$ at $10 \mathrm{~mA} \mathrm{~cm}^{-2}$ in alkaline conditions. Many studies have been carried out on the design of 2D MOFs for OER catalysis $[17,38,39]$.

In this study, we reported on a one-pot facile synthesis of $\mathrm{Ni} / \mathrm{Co}$ bimetallic MOF nanoplates $\left(\mathrm{Ni}_{x} \mathrm{Co}_{y}\right.$-bpy $\left.(\mathrm{PyM})\right)$ with a well-defined 2D morphology, which could be adopted directly as efficient OER electrocatalysts in alkaline conditions. With pyridine as the growth inhibitor in solvothermal method, the MOFs were obtained in the form of 2D rectangular nanoplates with a thickness of less than $20 \mathrm{~nm}$ and aspect ratio larger than 50. Among the $\mathrm{Ni}_{x} \mathrm{Co}_{y}$-bpy(PyM) MOF nanoplates, the $\mathrm{Ni}_{0.5} \mathrm{Co}_{1.5}$-bpy (PyM) displayed the best OER electrocatalytic activity with a low overpotential of $256 \mathrm{mV}$ at $10 \mathrm{~mA} \mathrm{~cm}^{-2}$ and a small Tafel slope of $81.8 \mathrm{mV} \mathrm{dec}^{-1}$ in $1.0 \mathrm{~mol} \mathrm{~L}^{-1} \mathrm{KOH}$ solution. In addition, the $\mathrm{Ni}_{0.5} \mathrm{Co}_{1.5}$-bpy $(\mathrm{PyM})$ exhibited long-term electrochemical stability for $3000 \mathrm{CV}$ cycles. The in situ formed active species during the OER elec- trocatalysis were also investigated in this study to explore the origin of the high OER activity. The in situ formed metal hydroxide and oxyhydroxide as well as its inherited 2D nanoplate morphology and optimized bimetallic ratio could provide an improved platform to deliver outstanding OER catalytic activity.

\section{EXPERIMENTAL SECTION}

\section{Preparation of 2D MOF nanoplates}

In a $50-\mathrm{mL}$ Teflon-lined stainless autoclave, 4,4'-bipyridine $(2 \mathrm{mmol}, 0.31 \mathrm{~g})$ and $\mathrm{NiSO}_{4} \cdot 6 \mathrm{H}_{2} \mathrm{O} / \mathrm{CoSO}_{4} \cdot 7 \mathrm{H}_{2} \mathrm{O}$ were dissolved in $15 \mathrm{~mL}$ of water. After $10 \mathrm{~min}$ of stirring, pyridine (18.6 mmol, $1.5 \mathrm{~g}$ ) and $8 \mathrm{~mL}$ of $\mathrm{EtOH}$ was added dropwise into the former solution under stirring. The solution was kept stirring for another $10 \mathrm{~min}$. The autoclave was then sealed and heated at $100^{\circ} \mathrm{C}$ for $24 \mathrm{~h}$. After natural cooling to the room temperature, solid products were collected by centrifugation. Then the products were washed with ethanol $(10 \mathrm{~mL} \times 3)$ and water $(10 \mathrm{~mL} \times 3)$ and dried at room temperature under vacuum.

Similarly, for the syntheses of other groups of nanoplates, the mixtures were heated at $100^{\circ} \mathrm{C}$ for $12 / 36 \mathrm{~h}$, or at $80 / 120^{\circ} \mathrm{C}$ for $24 \mathrm{~h}$. The detailed molar quantities of each reactants are shown in Supplementary information.

\section{Fabrication of working electrodes}

To fabricate the working electrodes, the as-synthesized MOFs ( $3 \mathrm{mg}$ ), and Nafion solution $(5 \mathrm{wt} \%, 25 \mu \mathrm{L})$ were mixed with $250 \mu \mathrm{L}$ of water and $250 \mu \mathrm{L}$ of ethanol, followed by ultrasonication for $1 \mathrm{~h}$. The dispersion $(5 \mu \mathrm{L})$ was deposited on the surface of a glassy carbon electrode (GCE) with a loading density of $0.40 \mathrm{mg} \mathrm{cm}^{-2}$ and dried at room temperature.

\section{Electrochemical measurement}

The electrochemical water oxidation was carried out on an electrochemical working station (CHI 760E, Shanghai Chenhua). A conventional three-electrode system was implemented for all the electrochemical measurements by utilizing a GCE (diameter: $3.0 \mathrm{~mm}$ ) as the working electrode, a graphite rod as the counter electrode, and a $\mathrm{Hg} /$ $\mathrm{HgO}$ electrode as the reference electrode in nitrogenbubbled $1.0 \mathrm{~mol} \mathrm{~L}^{-1} \mathrm{KOH}$ electrolyte. According to the Nernst equation $\left(E_{\mathrm{RHE}}=E_{\mathrm{Hg} / \mathrm{HgO}}+0.059 \mathrm{pH}+0.098\right)$, the current density was normalized to the geometrical surface area and the measured potential vs. $\mathrm{Hg} / \mathrm{HgO}$ was converted to a reversible hydrogen electrode (RHE). Cyclic voltammograms (CVs) were obtained at a scan rate of $50 \mathrm{mV} \mathrm{s}^{-1}$ and $\mathrm{CV}$ data were collected until stabilization 
after several times of scanning. The linear sweep voltammograms (LSVs) were obtained with a scan rate of $5 \mathrm{mV} \mathrm{s}^{-1}$. The working electrodes were scanned several times until the signals were stabilized and then LSV data were collected. The electrochemical impedance spectroscopy (EIS) measurements were conducted in the frequency range of $100 \mathrm{kHz}$ to $0.01 \mathrm{~Hz}$ at $1.53 \mathrm{~V}$.

\section{Determination of double-layer capacitance $\left(C_{\mathrm{dl}}\right)$}

The $C_{\mathrm{dl}}$ was determined by measuring CVs with multiple scan rates in non-Faradaic potential region. In this potential region, all measured currents were assumed to be associated with the double-layer charging. The potential range typically centered at the non-Faradaic region with a potential window of $0.1 \mathrm{~V}$. In this study, CVs were measured in a potential range of $1.02-1.22 \mathrm{~V} v s$. RHE at different scan rates.

\section{RESULTS AND DISCUSSION}

\section{Preparation and characterization of MOF nanoplates}

The 2D MOF nanoplates were synthesized via one-pot solvothermal reaction as shown in Scheme 1. Firstly, 4,4'bipyridine, $\mathrm{NiSO}_{4} \cdot 6 \mathrm{H}_{2} \mathrm{O}$ and $\mathrm{CoSO}_{4} \cdot 7 \mathrm{H}_{2} \mathrm{O}$ (with $\mathrm{Ni} / \mathrm{Co}$ molar ratio 1:3) were mixed and dissolved in water. Next, pyridine and $\mathrm{EtOH}$ were added dropwise into the solution. Then, the mixture was heated at $100^{\circ} \mathrm{C}$ for $24 \mathrm{~h}$ to obtain the target nanoplate $\mathrm{Ni}_{0.5} \mathrm{Co}_{1.5}$-bpy $(\mathrm{PyM})$. The synthesis procedure and molar concentrations are explained in detail in the Experimental Section.

The scanning electron microscopy (SEM) images reveal the $\mathrm{Ni}_{0.5} \mathrm{Co}_{1.5}$-bpy $(\mathrm{PyM})$ with a well-defined nanoplate morphology, relatively uniform scale and smooth surface (Fig. 1a). The lateral dimension of the rectangles ranges from hundreds of nanometers to approximately $1 \mu \mathrm{m}$. Transmission electron microscopy (TEM) image also demonstrates the nanoplate feature (Fig. 1b). The thickness of the $\mathrm{Ni}_{0.5} \mathrm{Co}_{1.5}$-bpy $(\mathrm{PyM})$ nanoplates was measured to be about $20 \mathrm{~nm}$ by an atomic force microscope (AFM) (Fig. 1c), indicating an aspect ratio as large as 50 . Pyridine was utilized for inhibiting the growth in the vertical direction to obtain the $2 \mathrm{D}$ morphology. As depicted in Scheme 1, 4,4'-bipyridine is a rod-like bidentate ligand that can link metals and help the growth of MOF in all dimensions. Pyridine is just half of the 4,4'-bipyridine and a monodentate ligand. Thus, it coordinates with metal atoms and plays the role of an inhibitor for layer stacking. $\mathrm{Ni}_{0.5} \mathrm{Co}_{1.5}$-bpy $(\mathrm{PyM})$ nanoplates grow faster in the lateral direction, which results in a lamellar morphology. In this study, to demonstrate the modulation effect of pyridine,

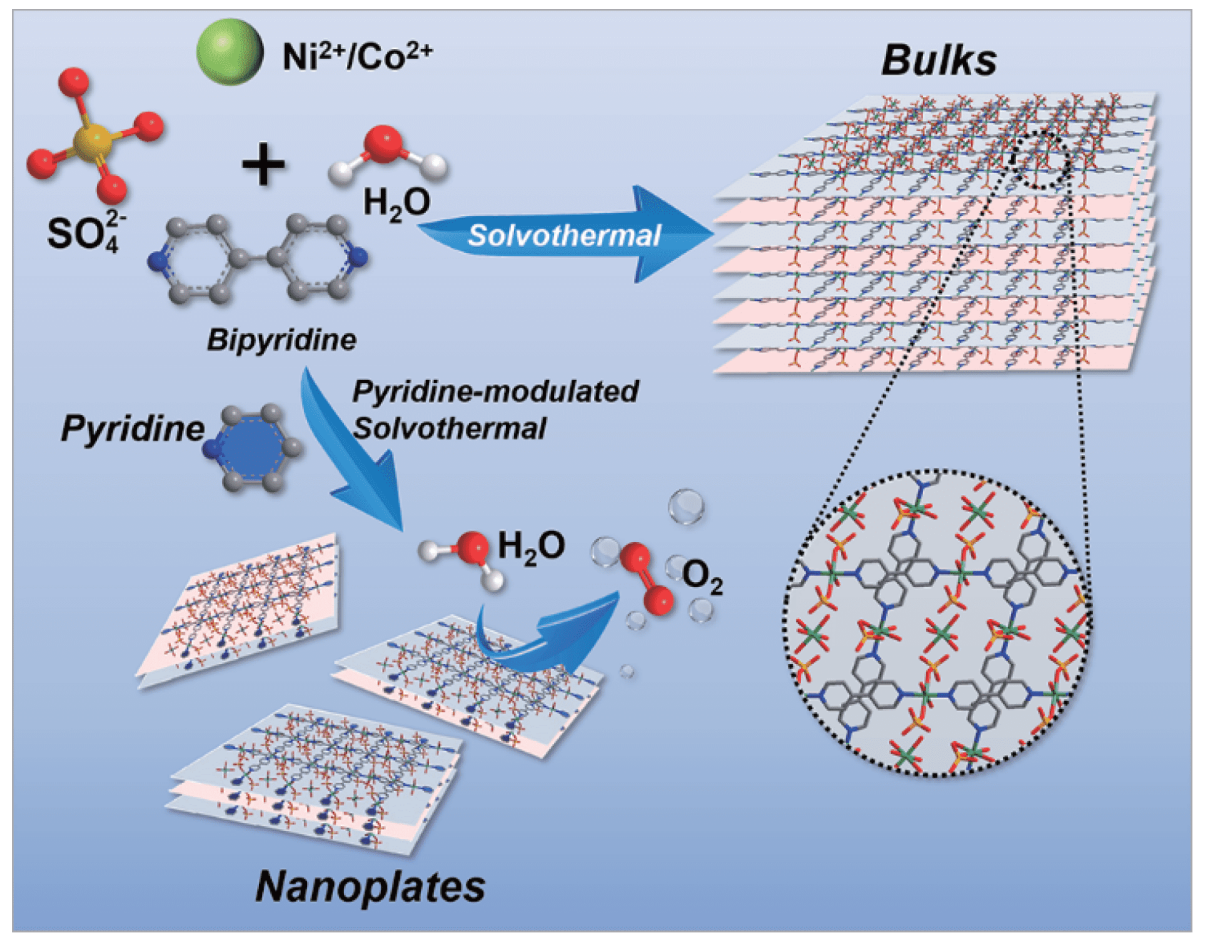

Scheme 1 Schematic illustration of the Ni/Co MOF nanoplates $\mathrm{Ni}_{x} \mathrm{Co}_{y}$-bpy(PyM) and cuboid MOF bulks $\mathrm{Ni}_{x} \mathrm{Co}_{y}$-bpy for the oxygen evolution reaction. 

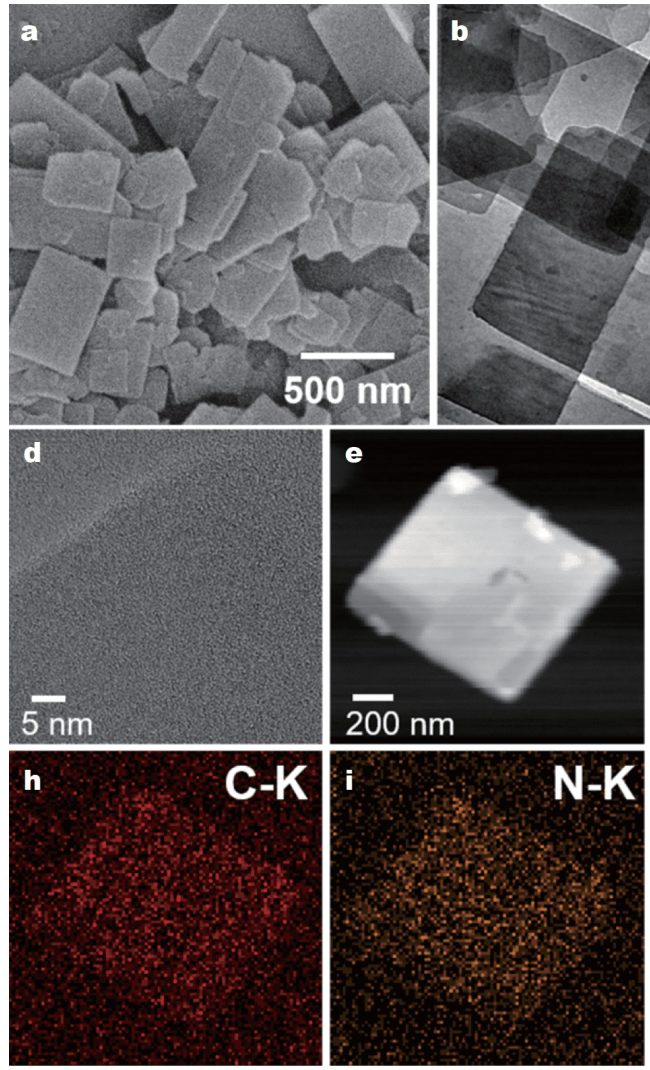
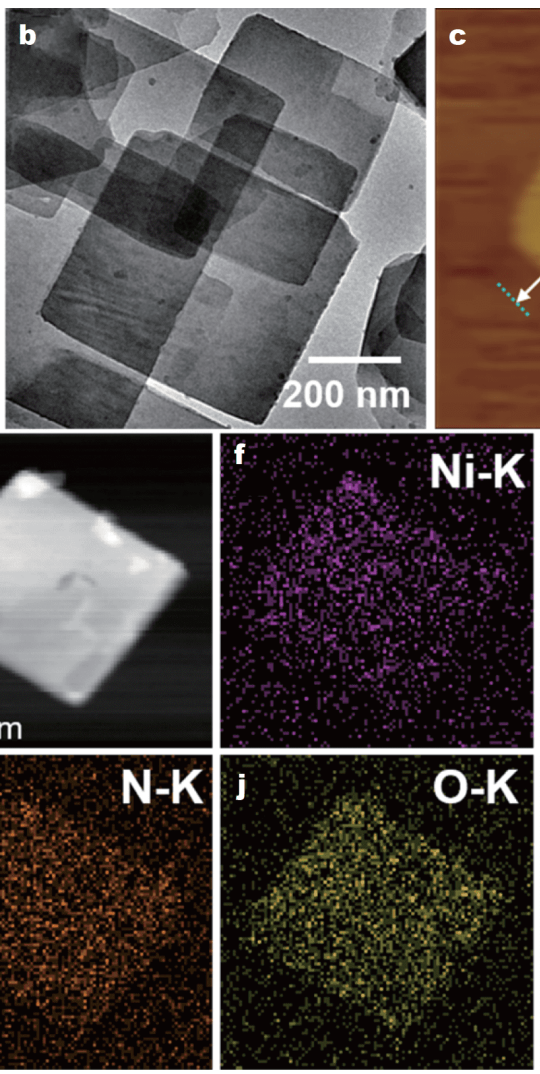
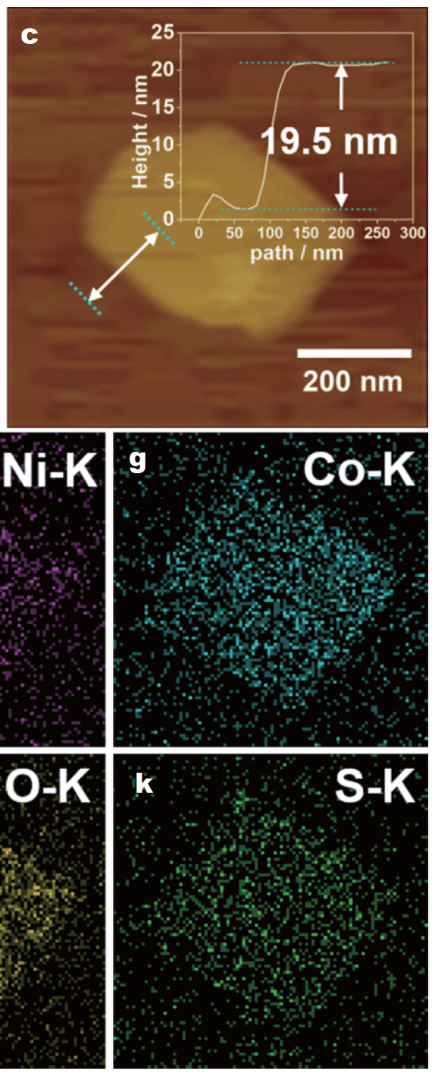

Figure 1 Morphological and structural characterizations of $\mathrm{Ni}_{0.5} \mathrm{Co}_{1.5}-\mathrm{bpy}(\mathrm{PyM})$. (a) SEM and (b) TEM images of $\mathrm{Ni}{ }_{0.5} \mathrm{Co}_{1.5}-\mathrm{bpy}(\mathrm{PyM})$. (c) $\mathrm{AFM}$ image of $\mathrm{Ni}_{0.5} \mathrm{Co}_{1.5}$-bpy (PyM), inset: measured thickness of individual nanoplate. (d) HRTEM image of $\mathrm{Ni}_{0.5} \mathrm{Co}_{1.5}$-bpy(PyM). (e) High-angle annular dark-field scanning transmission electron microscopy image of $\mathrm{Ni}_{0.5} \mathrm{Co}_{1.5}$ bpy $(\mathrm{PyM})$ and corresponding EDX elemental mapping images of (f) $\mathrm{Ni}$, ( $\mathrm{g}$ ) Co, (h) C, (i) N, (j) O and (k) S in $\mathrm{Ni}_{0.5} \mathrm{Co}_{1.5}$-bpy(PyM).

$\mathrm{Ni} / \mathrm{Co}$ MOFs were synthesized without the addition of pyridine as well, to produce micron-scale cuboid MOF bulks Ni-bpy and Co-bpy. The Ni-bpy bulks had lengths ranging from 20 to $60 \mu \mathrm{m}$, whereas the Co-bpy bulks had lengths ranging from 50 to $500 \mu \mathrm{m}$ as investigated by SEM (Fig. S1). The clear difference between the nanoplates and the micron-scale cuboid bulks demonstrates the successful modification in the morphology and scale via a simple procedure.

To illustrate the inner structure of $\mathrm{Ni}_{0.5} \mathrm{Co}_{1.5}$-bpy $(\mathrm{PyM})$, high-resolution TEM (HRTEM, Fig. 1d) characterization and energy dispersive X-ray (EDX) spectroscopy analyses were carried out. The lattice fringes of $\mathrm{Ni}_{0.5} \mathrm{Co}_{1.5}$-bpy (PyM) could not be observed in the HRTEM image as the MOF structures tended to be destroyed by the high-energy electron beam irradiation [40]. The EDX spectra demonstrate the presence of $\mathrm{Ni}, \mathrm{Co}, \mathrm{C}, \mathrm{N}, \mathrm{S}$ and $\mathrm{O}$ in the $\mathrm{Ni}_{0.5} \mathrm{Co}_{1.5}$-bpy (PyM) MOF (Fig. S2a). The S and O may originate from the counter sulfate ion. The EDX elemental mapping further proves the existence and homogeneous distribution of these elements (Fig. 1e-k). According to the $\mathrm{N}_{2}$ adsorption-desorption isotherms, the $\mathrm{Ni}_{0.5} \mathrm{Co}_{1.5}$-bpy $(\mathrm{PyM})$ exhibits a high Brunauer-EmmettTeller (BET) surface area of $851.5 \mathrm{~m}^{2} \mathrm{~g}^{-1}$ which could be ascribed to the unique 2D structure (Fig. S2b, c).

To investigate the electrocatalytic activity of the $\mathrm{Ni}_{x} \mathrm{Co}_{y^{-}}$ bpy(PyM) nanoplates, as well as the function of the bimetallic ions, the stoichiometric ratio of nickel and cobalt was varied to obtain other four groups of $\mathrm{Ni}_{x} \mathrm{Co}_{y}$-bpy (PyM) (Fig. S3). The total dosages of $\mathrm{NiSO}_{4} \cdot 6 \mathrm{H}_{2} \mathrm{O}$ and $\mathrm{CoSO}_{4} \cdot 7 \mathrm{H}_{2} \mathrm{O}$ were fixed as $2.0 \mathrm{mmol}$ with $\mathrm{Ni}$ :Co molar ratios of 1:0, 3:1, 1:1, and 0:1. The reaction conditions remained the same as that of $\mathrm{Ni}_{0.5} \mathrm{Co}_{1.5}$-bpy $(\mathrm{PyM})$ and the products were denoted as $\mathrm{Ni}$-bpy $(\mathrm{PyM}), \mathrm{Ni}_{1.5} \mathrm{Co}_{0.5}$-bpy (PyM), $\mathrm{Ni}_{1} \mathrm{Co}_{1}$-bpy $(\mathrm{PyM})$, Co-bpy(PyM), respectively. Similar to $\mathrm{Ni}_{0.5} \mathrm{Co}_{1.5}$-bpy $(\mathrm{PyM})$, the four products also reveal nanoplate morphologies as shown in SEM and TEM images (Figs 2a1-d1, a2-d2). When nickel was predominant in the MOF (i.e., in Ni-bpy(PyM)), the corners of the nanoplates became sharper. The rectan- 

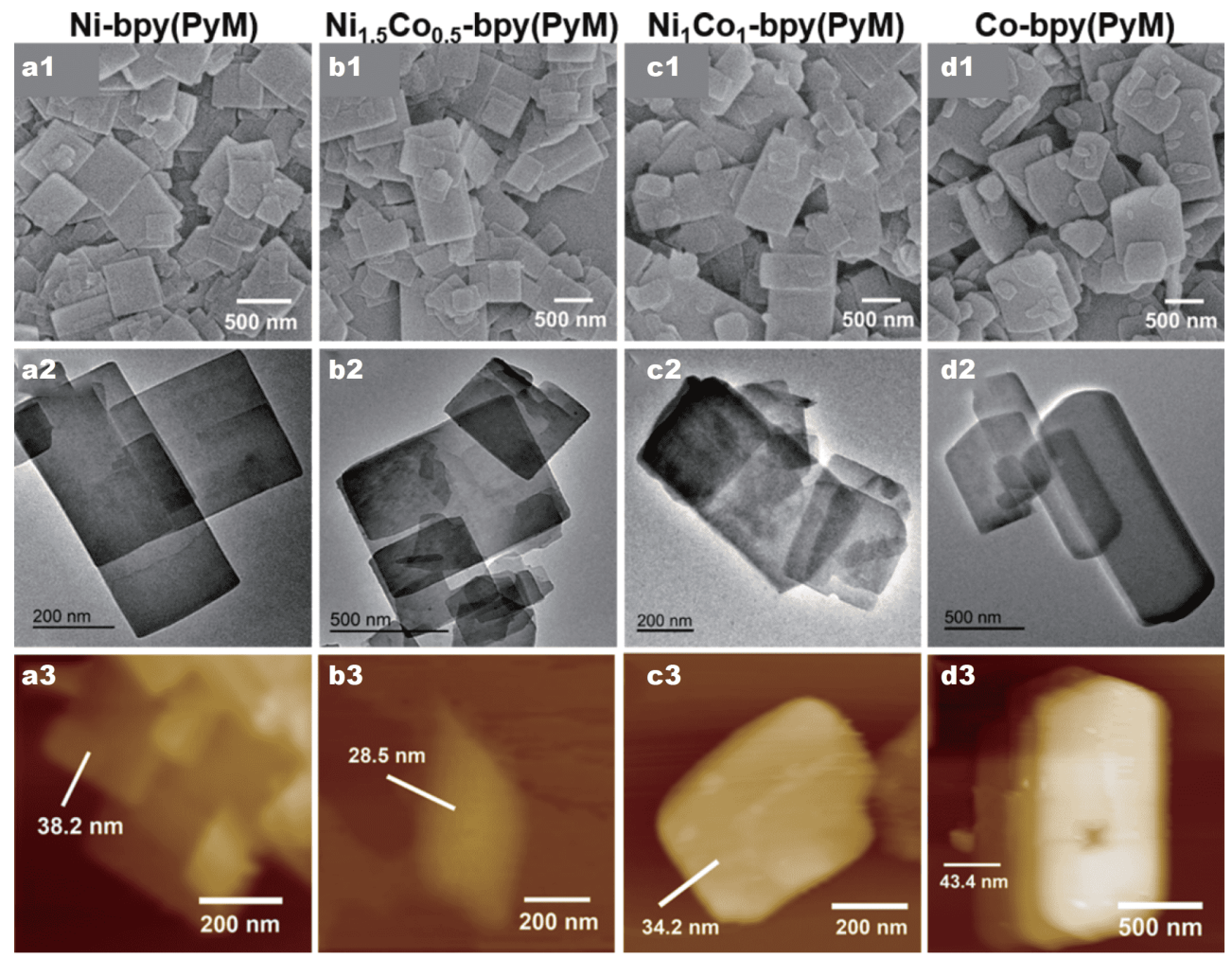

Figure 2 Morphological characterizations of $\mathrm{Ni}_{x} \mathrm{Co}_{y}$-bpy(PyM). (a1-d1) SEM, (a2-d2) TEM and (a3-d3) AFM images of (a) Ni-bpy(PyM), (b) $\mathrm{Ni}_{1.5} \mathrm{Co}_{0.5}$-bpy(PyM), (c) $\mathrm{Ni}_{1} \mathrm{Co}_{1}-\mathrm{bpy}(\mathrm{PyM})$, and (d) Co-bpy(PyM) nanoplates. The measured thicknesses of the nanoplates are marked in (a3-d3).

gular surfaces of the nanoplates became arc-shaped on the two opposite sides as the proportion of cobalt ions increased in the MOFs. The thicknesses of the MOF nanoplates were also calculated to be ranging from 28.5 to $43.4 \mathrm{~nm}$ via AFM (Fig. 2a3-d3). The UV-vis absorption spectra of $\mathrm{Ni}_{x} \mathrm{Co}_{y}$-bpy (PyM) were converted from optical diffuse reflectance spectra by using the Kubelka-Munk function (Fig. S4a). With the Co(II) content increasing, the absorption band in the red region decreased, while the absorption band in the blue-green region increased. As a result, the color of the MOF powder changed from light green to brown (Fig. S3 upper row). Tauc plots were drawn from the absorption spectra and the optical band gaps were determined. The band gap of $\mathrm{Ni}_{0.5} \mathrm{Co}_{1.5}$-bpy (PyM) was estimated to be $2.73 \mathrm{eV}$, which was narrower than those of the other four nanoplates, as well as those of several semi-conductor materials (Fig. S4b) [41]. The narrow band gap could improve its catalytic performance significantly. The $\mathrm{Ni}_{x} \mathrm{Co}_{y}$-bpy(PyM) nanoplates remained well-dispersed in ethanol solution and exhibited Tyndall effect due to the scattering of light of the nanoplates in the colloidal suspensions (Fig. S3 bottom row) [42].

The solvothermal reaction conditions of the $\mathrm{Ni} / \mathrm{Co}$ bi- metallic MOFs were optimized by tuning the reaction temperature and time. With variations of solvothermal temperature $\left(80\right.$ and $\left.120^{\circ} \mathrm{C}\right)$, the as-synthesized nanoplates showed nonuniform distribution in the lateral direction unlike the ones synthesized under $100^{\circ} \mathrm{C}$ (Fig. S5). In the other group, the samples were synthesized under $100^{\circ} \mathrm{C}$ with different reaction times. An insufficient time $(12 \mathrm{~h})$ resulted in irregular shaped products with similar thicknesses. The nanoplates were of uniform size with sufficient heating $(36 \mathrm{~h})$; however, the thickness of the samples could not be controlled (Fig. S6). Therefore, $\mathrm{Ni}_{x} \mathrm{Co}_{y}$-bpy $(\mathrm{PyM})$ showed the most uniform lateral size and thickness with the solvothermal synthesis carried out under $100^{\circ} \mathrm{C}$ for $24 \mathrm{~h}$.

The X-ray diffraction (XRD) patterns of the $\mathrm{Ni}_{x} \mathrm{Co}_{y}$-bpy (PyM) nanoplates and the Ni-bpy and Co-bpy bulks were analyzed (Fig. 3a). The XRD patterns of Ni-bpy and Cobpy displayed very good crystallinity and were in close agreement with previously reported $\mathrm{Co} \mathrm{MOFs}\left(\left[\mathrm{Co}_{3}\left(4,4{ }^{\prime}-\right.\right.\right.$ bpy $\left.)_{2}\left(\mathrm{SO}_{4}\right)_{3}\left(\mathrm{H}_{2} \mathrm{O}\right)_{11}\right]_{n}$, No. 826371, space group of $P-1$, Cambridge Crystallographic Data Centre) [43]. The MOF structure contained three crystallographically unique $M$ (II) centers which were all in six-coordinated environ- 

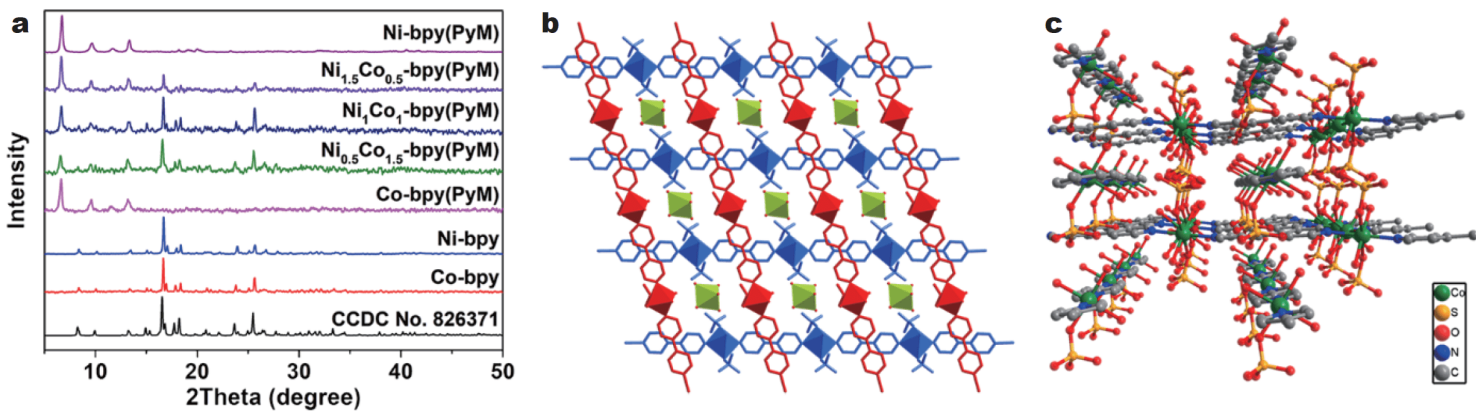

Figure 3 The XRD patterns and crystal structures of the MOFs. (a) Powder XRD patterns of the Ni/Co MOFs. (b, c) Structural schematic graphs of Co-bpy $\left[\mathrm{Co}_{3}\left(4,4^{\prime}-\text {-bpy }\right)_{2}\left(\mathrm{SO}_{4}\right)_{3}\left(\mathrm{H}_{2} \mathrm{O}\right)_{11}\right]_{n}$. (b) Crystal stacking along $a$ axis. The coordination of cobalt: octahedrally coordinated in three patterns. (c) Crystal stacking along $c$ axis.

ments (Fig. 3b). One M(II) center was coordinated with two 4,4'-bipyridine (4,4'-bpy) ligands, one sulfate ion and three $\mathrm{H}_{2} \mathrm{O}$ molecules (blue octahedron). The second $\mathrm{M}$ (II) center was coordinated with two 4,4'-bpy ligands and four $\mathrm{O}$ atoms from two monodentate sulfate ions and two $\mathrm{H}_{2} \mathrm{O}$ ligands (red octahedron). The third $\mathrm{M}(\mathrm{II})$ center formed a hexaaquametal (II) ion (green octahedron). There were two different 1D chains (marked red and blue in Fig. 3b) which were arranged in a cross-like pattern around the mid-point of the 4,4'-bpy ligands. The O$\mathrm{H}$... O hydrogen-bond between the $\mathrm{H}_{2} \mathrm{O}$ molecules and the sulfate anions resulted in a $3 \mathrm{D}$ supramolecular network (Fig. 3c) [43]. The fraction peaks (at $6.7^{\circ}, 9.7^{\circ}$, and $13.3^{\circ}$ ) of Ni-bpy(PyM) and Co-bpy(PyM) were distinctly different from that of the samples without pyridine. In those two cases, the addition of pyridine inhibited the growth of the framework and induced the formation of a new phase and coordination structure. For the pyridine-participated bimetallic MOF samples, the diffraction peaks at $16.6^{\circ}$ (020), $16.8^{\circ}(002), 17.7^{\circ}(112), 18.2^{\circ}$ (102), 23.6 ${ }^{\circ}$ (102), and $25.5^{\circ}(200)$ agreed well with those of the Ni-bpy and Co-bpy MOFs, while the diffraction peaks at $6.7^{\circ}, 9.7^{\circ}$, and $13.3^{\circ}$ agreed with those obtained with the single metallic Ni-bpy(PyM) and Co-bpy(PyM) MOF nanoplates (Fig. 3a). These results reveal that the bimetallic MOF is a mixture of the MOF structures both with and without the addition of pyridine.

The structures of the as-synthesized $\mathrm{Ni}_{x} \mathrm{Co}_{y}$-bpy $(\mathrm{PyM})$ nanoplates were further studied by Fourier transform infrared (FT-IR) spectroscopy (Fig. S7). Similar absorption bands could be found in the IR spectra of the seven samples. The results demonstrated that the $\mathrm{Ni}_{x} \mathrm{Co}_{y}$-bpy (PyM) nanoplates retained the same functional groups after addition of pyridine. The strong absorbed peaks at $1610,1537,1490$ and $1413 \mathrm{~cm}^{-1}$ demonstrated that there was a pyridine skeleton vibration in the MOF (Fig. S7 red area). The absorption peaks at 1110 and $632 \mathrm{~cm}^{-1}$ confirmed the presence of the coordinated $\mathrm{SO}_{4}{ }^{2-}$ ions (Fig. S7 blue area).

X-ray photoelectron spectra (XPS) were utilized to investigate the composition and chemical structure of the $\mathrm{Ni}_{x} \mathrm{Co}_{y}$-bpy(PyM) samples (Fig. 4a and Fig. S8). Taking $\mathrm{Ni}_{0.5} \mathrm{Co}_{1.5}$-bpy $(\mathrm{PyM})$ as an example, the survey spectrum of this sample demonstrated the presence of $\mathrm{Co}, \mathrm{Ni}, \mathrm{C}, \mathrm{N}$, $\mathrm{S}$ and $\mathrm{O}$ (Fig. S8d). The characteristic peaks of Co $2 \mathrm{p}$ at 797.4 and $781.5 \mathrm{eV}$ in the high-resolution XPS spectrum corresponded to the $\mathrm{Co}^{2+} 2 \mathrm{p}_{1 / 2}$ and $2 \mathrm{p}_{3 / 2}$ energy levels, respectively (Fig. 4a). Furthermore, in the high-resolution Ni $2 \mathrm{p}$ spectra of $\mathrm{Ni}_{0.5} \mathrm{Co}_{1.5}$-bpy $(\mathrm{PyM})$, two peaks located at 856.1 and $873.7 \mathrm{eV}$ could be assigned to $\mathrm{Ni}^{2+} 2 \mathrm{p}_{3 / 2}$ and $2 \mathrm{p}_{1 / 2}$, respectively (Fig. $4 \mathrm{~b}$ ) $[20,44]$. The $\mathrm{N}$ 1s spectrum could be deconvoluted into two peaks centered at 399.7 and $401.3 \mathrm{eV}$, which could be assigned to pyrrolic $\mathrm{N}$ and pyridinic N, respectively (Fig. 4c) [17]. In the high-resolution XPS spectrum of $C 1$ s, the peaks at 285.2 and $286.0 \mathrm{eV}$ corresponded to $\mathrm{C}-\mathrm{N}$ and $\mathrm{C}-\mathrm{C}$ from the pyridine or 4,4'-bipyridine ligands (Fig. 4d) [45]. Ni 2p and Co $2 p$ XPS spectra revealed the $\mathrm{Ni} / \mathrm{Co}$ ratios on the surface of the nanoplates, which were 2.16 for $\mathrm{Ni}_{1.5} \mathrm{Co}_{0.5^{-}}$ bpy(PyM), 0.94 for $\mathrm{Ni}_{1} \mathrm{Co}_{1}$-bpy(PyM), and 0.37 for $\mathrm{Ni}_{0.5}$ $\mathrm{Co}_{1.5}$-bpy(PyM) (Fig. S9). Meanwhile, the $\mathrm{Ni} / \mathrm{Co}$ atomic ratios in the bimetallic MOFs were determined to be 2.32, 1.01 and 0.40 individually, according to the inductively coupled plasma optical emission spectrometry (ICP-OES) analysis. The results were close to the dosage ratios of $\mathrm{Ni}^{2+}$ and $\mathrm{Co}^{2+}$ utilized in the synthesis, which demonstrated the efficient regulation and modification of the solvothermal synthesis.

\section{Electrocatalytic performance of MOF nanoplates}

The electrochemical performances of the $\mathrm{Ni}_{x} \mathrm{Co}_{y}$-bpy (РyM) samples were measured with a typical three-elec- 

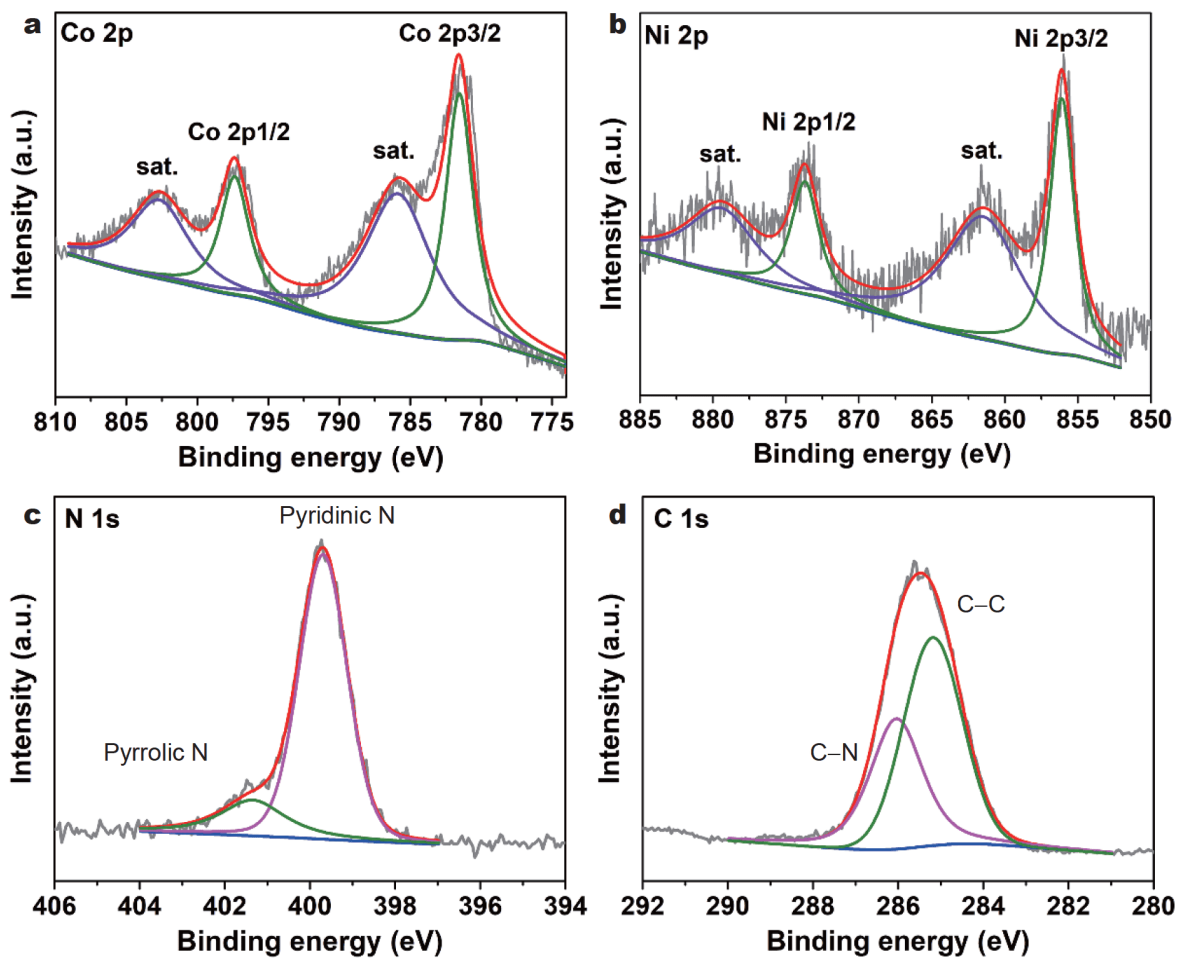

Figure 4 XPS of $\mathrm{Ni}_{0.5} \mathrm{Co}_{1.5}$-bpy(PyM). High-resolution (a) Co 2p, (b) Ni 2p, (c) N 1s, and (d) C 1s spectra.

trode system in a $1.0 \mathrm{~mol} \mathrm{~L}^{-1} \mathrm{KOH}$ solution. LSV was utilized to obtain the polarization curves (Fig. 5a). Among the $\mathrm{Ni}_{x} \mathrm{Co}_{y}$-bpy(PyM) MOFs, $\mathrm{Ni}_{0.5} \mathrm{Co}_{1.5}$-bpy (PyM) displayed the highest current density at the same potential. To obtain a current density of $10 \mathrm{~mA} \mathrm{~cm}{ }^{-2}$, the $\mathrm{Ni}_{0.5} \mathrm{Co}_{1.5}$. bpy(PyM) nanoplates needed an overpotential of $256 \mathrm{mV}$, which was the lowest among all the overpotentials for the $\mathrm{Ni}_{x} \mathrm{Co}_{y}$-bpy(PyM) MOFs. The results established that $\mathrm{Ni}_{0.5} \mathrm{Co}_{1.5}$-bpy (PyM) had the best OER performances with a pristine MOF as a catalyst (Table S2). The OER polarization curves of $\mathrm{Ni}_{0.5} \mathrm{Co}_{1.5}$-bpy $(\mathrm{PyM})$ after $i R$ correction revealed negligible changes compared with those before $i R$ correction (Fig. S10). The OER electrocatalytic kinetics of all the $\mathrm{Ni}_{x} \mathrm{Co}_{y}$-bpy(PyM) MOFs were obtained from the corresponding Tafel plots (Fig. 5b). The lower Tafel slope represented a faster enhancement of the OER catalysis with the potential increasing [46]. The Tafel slope of Co-bpy(PyM) $\left(69.1 \mathrm{mV} \mathrm{dec}^{-1}\right)$ was the smallest among those of the $\mathrm{Ni}_{x} \mathrm{Co}_{y}$-bpy $(\mathrm{PyM}) \mathrm{MOF}$, while the Tafel slope of $\mathrm{Ni}_{0.5} \mathrm{Co}_{1.5}$-bpy (PyM) was the smallest among those of the three bimetallic-bpy(PyM) MOF samples $\left(81.8 \mathrm{mV} \mathrm{dec}^{-1}\right)$. Thus, both types of nanoplates displayed favorable electrocatalytic kinetics for OER.

EIS was performed at a potential of $1.53 \mathrm{~V}$ to further explain the catalytic kinetics of $\mathrm{Ni}_{x} \mathrm{Co}_{y}$-bpy(PyM) nano- plates (Fig. S11). The Nyquist plots revealed that the single metallic-bpy(PyM) MOFs, namely Ni-bpy(PyM) and Co-bpy(PyM) had the largest and the smallest semicircular diameters, respectively in the high frequency region among the $\mathrm{Ni}_{x} \mathrm{Co}_{y}$-bpy $(\mathrm{PyM})$ nanoplates. The charge transfer resistance $\left(R_{\mathrm{ct}}\right)$ was calculated to be 57.13 and $8.47 \Omega$ for Ni-bpy(PyM) and Co-bpy(PyM), respectively. $\mathrm{Ni}_{0.5} \mathrm{Co}_{1.5}$-bpy (PyM) displayed the smallest $R_{\mathrm{ct}}$ at $12.95 \Omega$ among the bimetallic-bpy(PyM) MOFs, suggesting the fastest charge transfer process between the electrolyte and the catalyst [47]. Meanwhile, $\mathrm{Ni}_{0.5} \mathrm{Co}_{1.5^{-}}$ $\mathrm{bpy}(\mathrm{PyM})$ displayed a larger slope than the other bimetallic MOF nanoplates in the low frequency region, indicating a favorable diffusion rate for the ions and $\mathrm{O}_{2}$ [33]. The electrochemical active surface area (ECSA) of the catalyst plays a vital role in the OER catalysis and the $C_{\mathrm{dl}}$ is proportional to the ECSA [46]. The $C_{\mathrm{dl}}$ of $\mathrm{Ni}_{x} \mathrm{Co}_{y^{-}}$ bpy(PyM) nanoplates was measured by $\mathrm{CV}$ with various scan rates under the non-Faradaic potential $1.02-1.22 \mathrm{~V}$ (vs. RHE) without the redox processes. Similar to the results of the Tafel slope, the Co-bpy(PyM) MOFs showed a higher $C_{\mathrm{dl}}\left(10.63 \mathrm{mF} \mathrm{cm}^{-2}\right)$ as depicted in Fig. 5c (calculated from the corresponding CVs in Fig. S12). $\quad \mathrm{Ni}_{0.5} \mathrm{Co}_{1.5}$-bpy $(\mathrm{PyM})$ possessed the largest $C_{\mathrm{dl}}$ $\left(6.69 \mathrm{mF} \mathrm{cm}^{-2}\right)$ among the bimetallic-bpy(PyM) MOFs, 

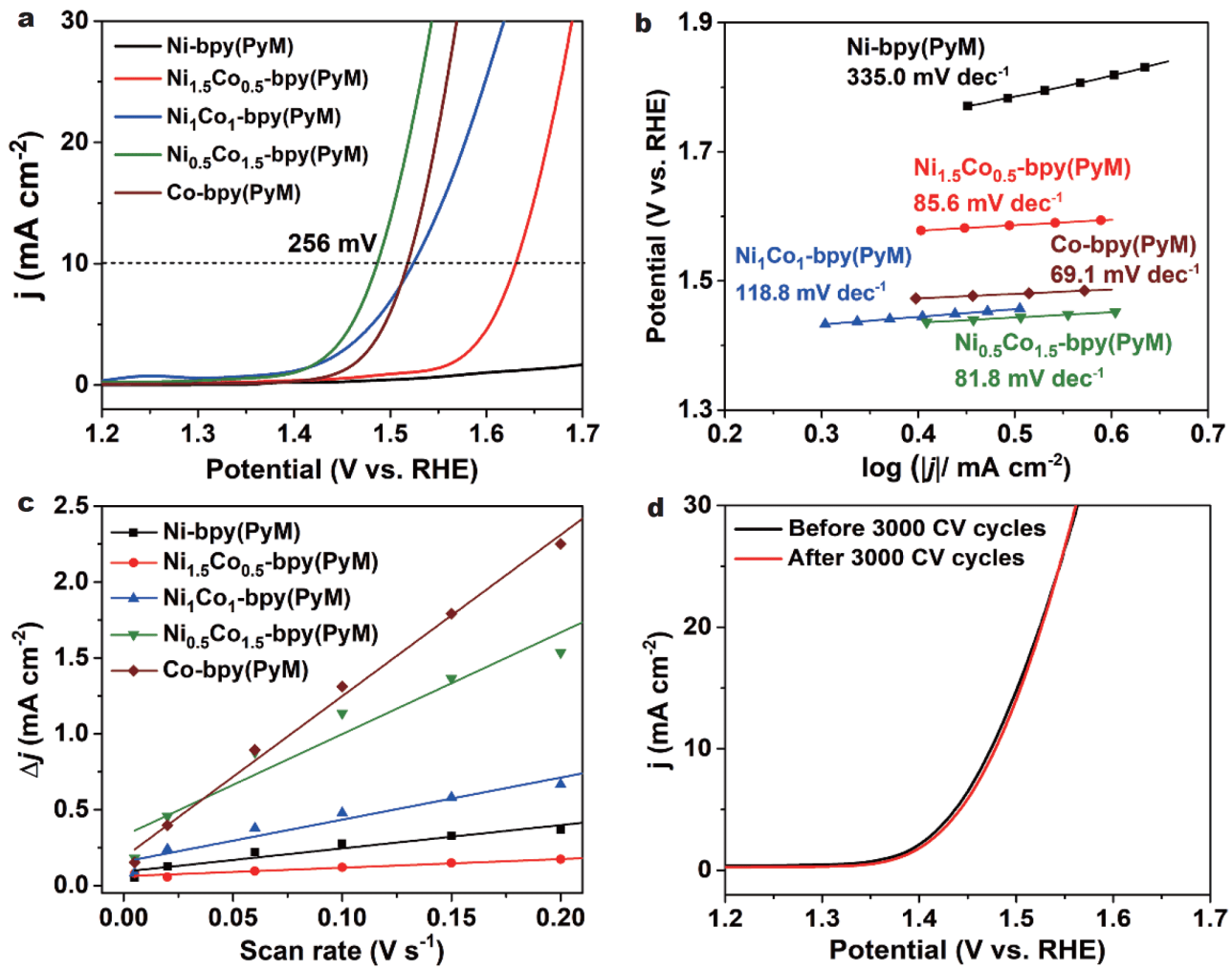

Figure 5 OER performance of $\mathrm{Ni}_{x} \mathrm{Co}_{y}$-bpy $(\mathrm{PyM})$. (a) OER polarization curves of $\mathrm{Ni}_{x} \mathrm{Co}_{y}$-bpy(PyM) in $1.0 \mathrm{~mol} \mathrm{~L}^{-1} \mathrm{KOH}$ at scan rate of $5 \mathrm{mV} \mathrm{s}{ }^{-1}$. (b) OER Tafel plots obtained from the OER polarization curves in (a). (c) Plots of the capacitive currents as a function of scan rate of $\mathrm{Ni}_{x} \mathrm{Co}_{y}$-bpy(PyM). (d) OER polarization curves of $\mathrm{Ni}_{0.5} \mathrm{Co}_{1.5}$-bpy(PyM) before and after $3000 \mathrm{CV}$ cycles.

indicating the greatest roughness of the electrode and the most active sites. The results suggest that the contribution of $\mathrm{Co}$ in the MOFs to the active surface area is crucial in promoting the OER catalytic performance.

The OER electrocatalytic performance of the cuboid MOF bulks Ni-bpy and Co-bpy were also investigated (Figs S13-S16) and summarized (Table S3). The comparison of Co-bpy(PyM) and Co-bpy revealed the significant positive effect of pyridine addition on the OER electrocatalysis. The Co-bpy(PyM) nanoplates possessed lower overpotential $(136 \mathrm{mV})$, better kinetics (22.3 $\mathrm{mV} \mathrm{dec}^{-1}$ lower in Tafel slope), better conductivity (9.37 less in $R_{\mathrm{ct}}$ ) as well as larger ECSA $\left(3.29 \mathrm{mF} \mathrm{cm}^{-2}\right.$ larger in $C_{\mathrm{dl}}$ ). It could be attributed to the pyridine modulation on the morphology, structure and phase. It was noteworthy that the contrast between OER performances of Ni-bpy(PyM) and Ni-bpy was not accordant with the Co MOFs. The Ni-bpy nanoplates displayed lower overpotential and smaller Tafel slope than Ni-bpy (PyM), suggesting the greater contribution of structure and phase than morphology on the electrocatalysis in this case. The single metallic Co MOFs (both Co-bpy(PyM) and Co-bpy) in this study were confirmed with better OER catalytic activity than the corresponding Ni MOFs. Meanwhile, Co-bpy(PyM) showed the best kinetics and conductivity (favorable for oxidation reaction), and the highest surface roughness (active for catalytic reaction), even though its overpotential was still higher than that of $\mathrm{Ni}_{0.5} \mathrm{Co}_{1.5}$-bpy(PyM). The phenomenon could be attributed to the contribution from the bimetal $\mathrm{Ni} / \mathrm{Co}$ ions in the MOFs. 1) The bimetallic MOF $\mathrm{Ni}_{x} \mathrm{Co}_{y}$-bpy(PyM) show mixed structures with the single metallic MOF Nibpy(PyM) and Co-bpy(PyM) and a 3D supramolecular network according to the XRD pattern (Fig. 3a). The unique structure might greatly contribute to the ion flux and conductivity. 2) The high specific surface area $\left(851.5 \mathrm{~m}^{2} \mathrm{~g}^{-1}\right)$, low thickness (favorable for electron transport) and narrow band gap of $\mathrm{Ni}_{0.5} \mathrm{Co}_{1.5}$-bpy(PyM) also contributed significantly to the electrocatalytic reaction. 3) It was reported previously that $\mathrm{Ni}$ was more beneficial than Co for the desorption of $\mathrm{OH}^{-}$in alkaline solutions and that Co had a higher activity for the Tafel steps than $\mathrm{Ni}[34,48]$. Therefore, for the $\mathrm{Ni}_{x} \mathrm{Co}_{y}$-bpy $(\mathrm{PyM})$, the $\mathrm{Ni}$ sites could accelerate water dissociation 
efficiently and the Co sites would be beneficial for gas generation and release [49]. By controlling the $\mathrm{Ni} / \mathrm{Co}$ ratio in the MOFs, stronger synergistic interaction between the bimetallic centers could be achieved for promoting OER performance. This synergistic effect of $\mathrm{Ni}$ and $\mathrm{Co}$ in $\mathrm{Ni}_{0.5} \mathrm{Co}_{1.5}$-bpy (PyM) results in the best catalyst performance among the $\mathrm{Ni}_{x} \mathrm{Co}_{y}$-bpy $(\mathrm{PyM})$ nanoplates.

The long-term durability of the $\mathrm{Ni}_{0.5} \mathrm{Co}_{1.5}$-bpy (PyM) catalyst was also explored. Continuous $\mathrm{CV}$ scanning in the range of 1.13-1.73 V (vs. RHE) was conducted with a scan rate of $100 \mathrm{mV} \mathrm{s}^{-1}$. LSV curves were compared at a scan rate of $5 \mathrm{mV} \mathrm{s}^{-1}$ to assess the durability before and after the continuous scan. The current density remained almost identical after $3000 \mathrm{CV}$ cycles ignoring minor variations, confirming its fine cycling stability (Fig. 5d). In addition, the current-time $(i-t)$ curve of $\mathrm{Ni}_{0.5} \mathrm{Co}_{1.5}$-bpy (PyM) showed slight current oscillations after $8 \mathrm{~h}$ of testing, which also indicated its excellent stability (Fig. S17). Over all, the excellent OER performance of the $\mathrm{Ni}_{0.5} \mathrm{Co}_{1.5}$-bpy (PyM) electrode displayed more potential applications compared with other MOF catalysts (Table S2).

\section{Investigation on the origination of high OER activity}

The morphological, structural and chemical variations were then investigated through the post-CV $\mathrm{Ni}_{0.5} \mathrm{Co}_{1.5^{-}}$
bpy(PyM) to understand the origins of the OER activity. The $\mathrm{Ni}_{0.5} \mathrm{Co}_{1.5}$-bpy (PyM) MOF nanoplates deposited on a GCE were characterized by SEM before and after 1000 CV cycles (Fig. S18). The electrode samples were also collected and observed under TEM after $1000 \mathrm{CV}$ cycles (Fig. 6a). The morphology of the MOFs was maintained, with smaller lateral sizes and thicknesses. These changes resulted in larger surface areas and more active sites. The ex-situ Raman spectra could further provide evidence of the structural variations (Fig. S19). The typical vibrational peaks of the organic ligands in the $\mathrm{Ni}_{0.5} \mathrm{Co}_{1.5}$-bpy (PyM) nanoplate at $1028,1293,1614 \mathrm{~cm}^{-1}$, and other minor peaks disappeared after the OER catalysis. It was accompanied with the appearance of two broad and weak bands located at approximately 495 and $625 \mathrm{~cm}^{-1}$ respectively, which could be attributed to the formation of $\mathrm{CoO}(\mathrm{OH})$ [50]. To further study the chemical state and composition of the $\mathrm{Ni}_{0.5} \mathrm{Co}_{1.5}$-bpy $(\mathrm{PyM})$ after the CV cycles, HRTEM and XPS spectra of the $\mathrm{Ni}_{0.5} \mathrm{Co}_{1.5}$-bpy $(\mathrm{PyM})$ were conducted. The HRTEM image revealed clear lattice fringes with interplanar distances of about $2.47,1.64,1.24$ and $2.77 \AA$, corresponding to (100), (104), (200) planes of $\mathrm{CoO}(\mathrm{OH})$ phase (JCPDS No. 26$1107)$ and (100) planes of $\mathrm{Co}(\mathrm{OH})_{2}$ (JCPDS No. 45-0031) (Fig. 6b). The selective area electron diffraction (SAED) pattern displayed several bright rings with discrete spots.
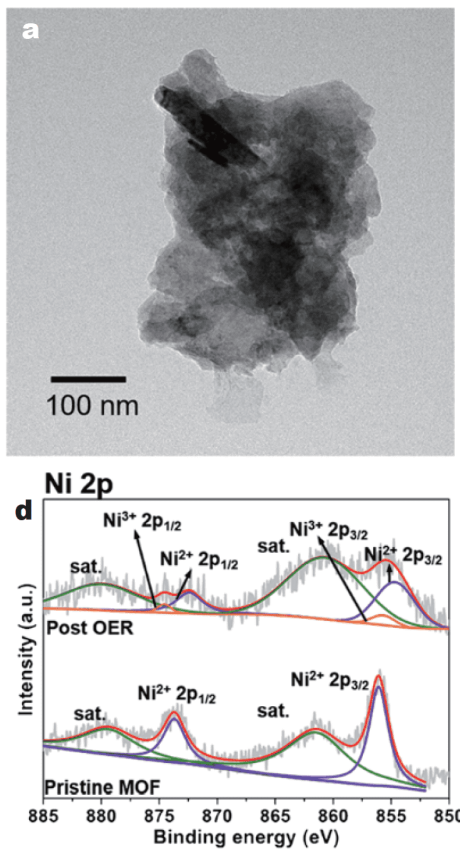
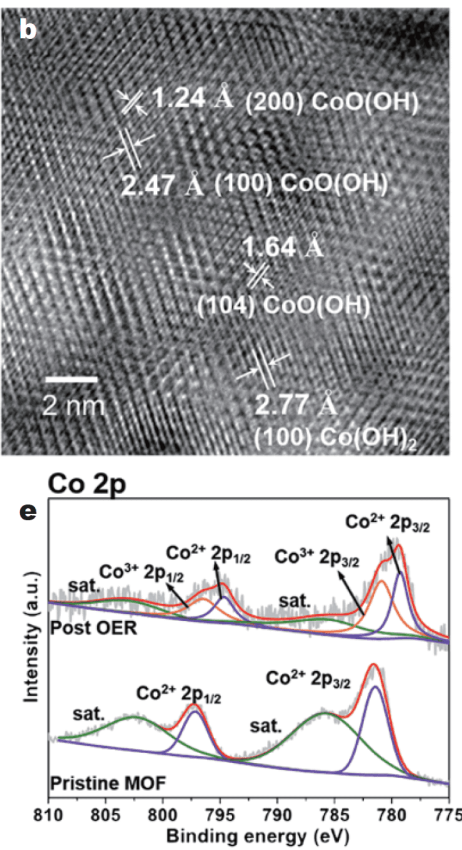
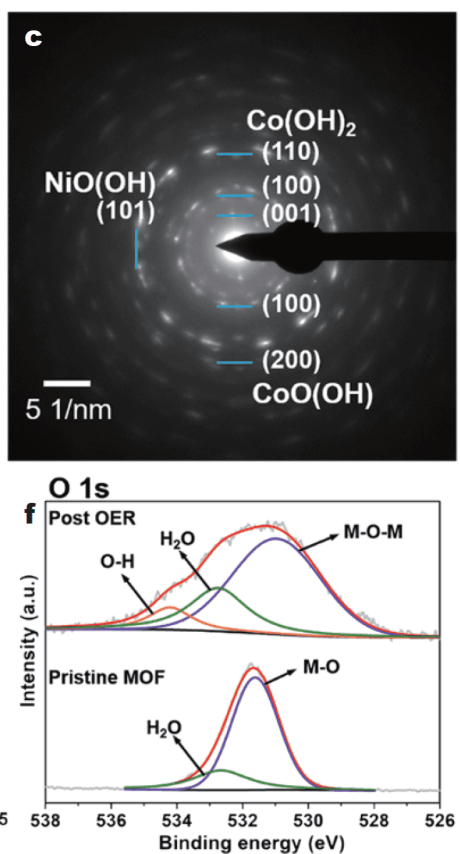

Figure 6 Post-CV structural characterization of $\mathrm{Ni}_{0.5} \mathrm{Co}_{1.5}$-bpy(PyM). (a) TEM, (b) HRTEM images and (c) SAED pattern of $\mathrm{Ni}_{0.5} \mathrm{Co}_{1.5}-\mathrm{bpy}(\mathrm{PyM})$ after $1000 \mathrm{CV}$ cycles. (d-f) High-resolution XPS spectra of (d) Ni 2p, (e) Co 2p and (f) O 1s of $\mathrm{Ni}_{0.5} \mathrm{Co}_{1.5}-\mathrm{bpy}(\mathrm{PyM})$ before (bottom) and after (upper) $1000 \mathrm{CV}$ cycles. 
They could be indexed to the $(001) /(100) /(110)$ planes of $\mathrm{Co}(\mathrm{OH})_{2},(100) /(200)$ planes of $\mathrm{CoO}(\mathrm{OH})$, and $(101)$ plane of $\mathrm{NiO}(\mathrm{OH})$ (JCPDS No. 27-0956) (Fig. 6c). The EDX spectra and the elemental mapping results confirmed the uniform distribution and considerable existence of $\mathrm{Ni}, \mathrm{Co}$ and $\mathrm{O}$, suggestive of their retention, in spite of the structural variation during the OER test (Figs S20, S21). Moreover, the XPS spectra of the $\mathrm{Ni}_{0.5}$ $\mathrm{Co}_{1.5}$-bpy (PyM) were investigated to analyze the changes of the chemical states. The survey spectrum agreed with the elemental mapping result which revealed the existence of $\mathrm{Ni}$, Co and $\mathrm{O}$ elements (Fig. S22). The electronic structures of $\mathrm{Ni}$ and $\mathrm{Co}$ were investigated through high-resolution spectra. The Ni $2 p$ spectra reflected that the peaks shifted to a lower binding energy (BE) after 1000 cycles compared with those of the pristine $\mathrm{Ni}_{0.5}$ $\mathrm{Co}_{1.5}$-bpy $(\mathrm{PyM})$ nanoplate $\left(\mathrm{Ni}^{2+} 2 \mathrm{p}_{3 / 2}\right.$ from 856.1 to $854.8 \mathrm{eV} ; \mathrm{Ni}^{2+} 2 \mathrm{p}_{1 / 2}$ from 873.7 to $872.4 \mathrm{eV}$ ) (Fig. 6d). This can be ascribed to the destruction of the $\mathrm{Ni}-\mathrm{N}$ coordination bond and the direct connection between the $\mathrm{Ni}$ and $\mathrm{O}$ atoms. This phenomenon increased the local electron density and resulted in a lower BE of Ni $2 p$ in $\mathrm{Ni}(\mathrm{OH})_{2}$ [51]. In addition, two new peaks at 874.6 and $855.8 \mathrm{eV}$ were observed after $1000 \mathrm{CV}$ cycles, which were derived from $\mathrm{Ni}^{3+}$ in the electrochemically formed $\mathrm{NiO}(\mathrm{OH})$. Similarly in the Co $2 \mathrm{p}$ high-resolution spectra, the down-shifted $\mathrm{Co}^{2+} 2 \mathrm{p}$ peaks $\left(\mathrm{Co}^{2+} 2 \mathrm{p}_{1 / 2}\right.$ from 797.2 to $794.7 \mathrm{eV} ; \mathrm{Co}^{2+} 2 \mathrm{p}_{3 / 2}$ from 781.4 to $\left.779.3 \mathrm{eV}\right)$ and the emergence of two new $\mathrm{Co}^{3+}$ peaks $(796.5$ and $780.9 \mathrm{eV}$ ) demonstrated the possible structural variation from the pristine $\mathrm{Ni}_{0.5} \mathrm{Co}_{1.5}$-bpy $(\mathrm{PyM})$ to $\mathrm{Co}(\mathrm{OH})_{2}$ and $\mathrm{CoO}(\mathrm{OH})$ (Fig. 6e) [52]. The high-resolution $\mathrm{O} 1 \mathrm{~s}$ spectra revealed that the dominant peaks originated from $\mathrm{H}_{2} \mathrm{O}(532.7 \mathrm{eV})$ and $\mathrm{M}-\mathrm{O}(531.6 \mathrm{eV})$ distinctly shifted to $534.2,532.8$, and $531.0 \mathrm{eV}$ from $\mathrm{O}-\mathrm{H}, \mathrm{H}_{2} \mathrm{O}$, and $\mathrm{M}-\mathrm{O}-\mathrm{M}$ groups, respectively, thus confirming the formation of oxyhydroxide during the electrocatalysis [35].

Therefore, the enhanced catalytic activity of $\mathrm{Ni}_{0.5} \mathrm{Co}_{1.5}$ bpy(PyM) could be attributed to the formation of active hydroxide and oxyhydroxide species evolved from the pristine MOF. Firstly, the inherited 2D nanoplate morphology with short transport paths, more specific surface area, and exposed potential active sites contribute significantly to the ion and molecular flux. In addition, the metal hydroxide and oxyhydroxide possess better electrical conductivity than the pristine $\mathrm{Ni}_{0.5} \mathrm{Co}_{1.5}$-bpy(PyM), thus, accelerating the electron transport. Moreover, the $\mathrm{Ni} /$ Co bimetallic synergistic interplay with an appropriate molar ratio optimizes the electronic structure and promotes the electrocatalytic process. As a result of these advantages, the bimetallic MOF nanoplates $\mathrm{Ni}_{0.5} \mathrm{Co}_{1.5}$-bpy (PyM) show advanced OER catalytic activity.

\section{CONCLUSIONS}

In conclusion, the $\mathrm{Ni} / \mathrm{Co}$ bimetallic MOF nanoplates $\mathrm{Ni}_{x} \mathrm{Co}_{y}$-bpy $(\mathrm{PyM})$ with well-defined 2D morphology were obtained through a one-pot facile solvothermal synthesis and can be adopted directly as efficient electrocatalysts. With pyridine as the growth modulator, all the MOFs were obtained as rectangular 2D nanoplates. Among the MOF nanoplates, $\mathrm{Ni}_{0.5} \mathrm{Co}_{1.5}$-bpy $(\mathrm{PyM})$ exhibited the best OER electrocatalytic activity with a low overpotential of $256 \mathrm{mV}$ at $10 \mathrm{~mA} \mathrm{~cm}^{-2}$ and a small Tafel slope of $81.8 \mathrm{mV} \mathrm{dec}^{-1}$ under alkaline conditions. The electrocatalyst also exhibited long-term electrochemical stability for $3000 \mathrm{CV}$ cycles. Moreover, the combined results indicated that the in situ formed active hydroxide and oxyhydroxide species from the pristine $\mathrm{Ni}_{0.5} \mathrm{Co}_{1.5}$-bpy (PyM) nanoplates with inherited 2D nanoplate morphology and optimized bimetallic ratio could provide an improved platform to deliver outstanding OER catalytic activity. It is expected that this work would contribute to the further exploration of unique MOF nanostructures to achieve advanced electrocatalysis performance.

\section{Received 15 February 2020; accepted 9 April 2020;}

published online 5 June 2020

1 Furukawa H, Cordova KE, O'Keeffe M, et al. The chemistry and applications of metal-organic frameworks. Science, 2013, 341: 1230444

2 Li B, Wen HM, Cui Y, et al. Emerging multifunctional metalorganic framework materials. Adv Mater, 2016, 28: 8819-8860

3 Liang Z, Zhao R, Qiu T, et al. Metal-organic framework-derived materials for electrochemical energy applications. EnergyChem, 2019, 1: 100001

4 Shi D, Zheng R, Sun MJ, et al. Semiconductive copper(I)-organic frameworks for efficient light-driven hydrogen generation without additional photosensitizers and cocatalysts. Angew Chem Int Ed, 2017, 56: 14637-14641

5 Yang X, Xu Q. Bimetallic metal-organic frameworks for gas storage and separation. Cryst Growth Des, 2017, 17: 1450-1455

6 Zhao M, Huang Y, Peng Y, et al. Two-dimensional metal-organic framework nanosheets: synthesis and applications. Chem Soc Rev, 2018, 47: 6267-6295

7 Xiao X, Zou L, Pang H, et al. Synthesis of micro/nanoscaled metalorganic frameworks and their direct electrochemical applications. Chem Soc Rev, 2020, 49: 301-331

8 Huang Y, Zhao M, Han S, et al. Growth of Au nanoparticles on 2D metalloporphyrinic metal-organic framework nanosheets used as biomimetic catalysts for cascade reactions. Adv Mater, 2017, 29: 1700102

9 Jiang W, Wang $\mathrm{H}$, Zhang $\mathrm{X}$, et al. Two-dimensional polymeric carbon nitride: structural engineering for optimizing photocatalysis. Sci China Chem, 2018, 61: 1205-1213 
10 Wang X, Li P, Li Z, et al. 2D MOF induced accessible and exclusive Co single sites for an efficient $O$-silylation of alcohols with silanes. Chem Commun, 2019, 55: 6563-6566

11 Chen S, Kang Z, Zhang X, et al. Highly active Fe sites in ultrathin pyrrhotite $\mathrm{Fe}_{7} \mathrm{~S}_{8}$ nanosheets realizing efficient electrocatalytic oxygen evolution. ACS Cent Sci, 2017, 3: 1221-1227

12 Xiao Y, Guo W, Chen $\mathrm{H}$, et al. Ultrathin 2D Cu-porphyrin MOF nanosheets as a heterogeneous catalyst for styrene oxidation. Mater Chem Front, 2019, 3: 1580-1585

$13 \mathrm{He} \mathrm{T,} \mathrm{Ni} \mathrm{B,} \mathrm{Ou} \mathrm{Y,} \mathrm{et} \mathrm{al.} \mathrm{Nanosheet-assembled} \mathrm{hierarchical} \mathrm{carbon}$ nanoframeworks bearing a multiactive center for oxygen reduction reaction. Small Methods, 2018, 2: 1800068

$14 \mathrm{Xu} \mathrm{X,} \mathrm{Lu} \mathrm{Y,} \mathrm{Yang} \mathrm{Y,} \mathrm{et} \mathrm{al.} \mathrm{Tuning} \mathrm{the} \mathrm{growth} \mathrm{of} \mathrm{metal-organic}$ framework nanocrystals by using polyoxometalates as coordination modulators. Sci China Mater, 2015, 58: 370-377

15 Zhao M, Lu Q, Ma Q, et al. Two-dimensional metal-organic framework nanosheets. Small Methods, 2017, 1: 1600030

16 Ding Y, Chen YP, Zhang X, et al. Controlled intercalation and chemical exfoliation of layered metal-organic frameworks using a chemically labile intercalating agent. J Am Chem Soc, 2017, 139: 9136-9139

17 Rui K, Zhao G, Chen Y, et al. Hybrid 2D dual-metal-organic frameworks for enhanced water oxidation catalysis. Adv Funct Mater, 2018, 28: 1801554

18 Zhao S, Wang Y, Dong J, et al. Ultrathin metal-organic framework nanosheets for electrocatalytic oxygen evolution. Nat Energy, 2016, 1: 16184

19 Wang X, Xiao H, Li A, et al. Constructing $\mathrm{NiCo} / \mathrm{Fe}_{3} \mathrm{O}_{4}$ heteroparticles within MOF-74 for efficient oxygen evolution reactions. J Am Chem Soc, 2018, 140: 15336-15341

20 Li FL, Wang P, Huang X, et al. Large-scale, bottom-up synthesis of binary metal-organic framework nanosheets for efficient water oxidation. Angew Chem Int Ed, 2019, 58: 7051-7056

21 Zhao K, Liu S, Ye G, et al. High-yield bottom-up synthesis of 2D metal-organic frameworks and their derived ultrathin carbon nanosheets for energy storage. J Mater Chem A, 2018, 6: 2166-2175

22 Pachfule P, Shinde D, Majumder M, et al. Fabrication of carbon nanorods and graphene nanoribbons from a metal-organic framework. Nat Chem, 2016, 8: 718-724

23 Tsuruoka T, Furukawa S, Takashima Y, et al. Nanoporous nanorods fabricated by coordination modulation and oriented attachment growth. Angew Chem Int Ed, 2009, 48: 4739-4743

24 Lin $\mathrm{Y}$, Chen $\mathrm{G}$, Wan $\mathrm{H}$, et al. 2D free-standing nitrogen-doped Ni$\mathrm{Ni}_{3} \mathrm{~S}_{2} @$ carbon nanoplates derived from metal-organic frameworks for enhanced oxygen evolution reaction. Small, 2019, 15: 1900348

25 Zhu B, Xia D, Zou R. Metal-organic frameworks and their derivatives as bifunctional electrocatalysts. Coord Chem Rev, 2018, 376: $430-448$

$26 \mathrm{Xu} \mathrm{Y,} \mathrm{Li} \mathrm{Q,} \mathrm{Xue} \mathrm{H,} \mathrm{et} \mathrm{al.} \mathrm{Metal-organic} \mathrm{frameworks} \mathrm{for} \mathrm{direct}$ electrochemical applications. Coord Chem Rev, 2018, 376: 292-318

27 Zhang S, Ye H, Hua J, et al. Recent advances in dye-sensitized photoelectrochemical cells for water splitting. EnergyChem, 2019, 1: 100015

28 Sun Y, Zhang X, Luo M, et al. Ultrathin PtPd-based nanorings with abundant step atoms enhance oxygen catalysis. Adv Mater, 2018, 30: 1802136

29 Jin H, Guo C, Liu X, et al. Emerging two-dimensional nanomaterials for electrocatalysis. Chem Rev, 2018, 118: 6337-6408

30 Han N, Zhao F, Li Y. Ultrathin nickel-iron layered double hydroxide nanosheets intercalated with molybdate anions for elec- trocatalytic water oxidation. J Mater Chem A, 2015, 3: 16348 16353

31 Huang X, Wang Y, Li W, et al. Noble metal-free catalysts for oxygen reduction reaction. Sci China Chem, 2017, 60: 1494-1507

32 Tao L, Lin CY, Dou S, et al. Creating coordinatively unsaturated metal sites in metal-organic-frameworks as efficient electrocatalysts for the oxygen evolution reaction: Insights into the active centers. Nano Energy, 2017, 41: 417-425

33 Zhang $\mathrm{X}$, Li X, Li R, et al. Highly active core-shell carbon/ $/ \mathrm{NiCo}_{2} \mathrm{O}_{4}$ double microtubes for efficient oxygen evolution reaction: Ultralow overpotential and superior cycling stability. Small, 2019, 15: 1903297

34 Zhang R, Wang X, Yu S, et al. Ternary $\mathrm{NiCo}_{2} \mathrm{P}_{x}$ nanowires as $\mathrm{pH}$ universal electrocatalysts for highly efficient hydrogen evolution reaction. Adv Mater, 2017, 29: 1605502

35 Qian Q, Li Y, Liu Y, et al. Ambient fast synthesis and active sites deciphering of hierarchical foam-like trimetal-organic framework nanostructures as a platform for highly efficient oxygen evolution electrocatalysis. Adv Mater, 2019, 31: 1901139

36 Chen $\mathrm{Z}$, Zhao $\mathrm{H}$, Zhang J, et al. IrNi nanoparticle-decorated flower-shaped $\mathrm{NiCo}_{2} \mathrm{O}_{4}$ nanostructures: controllable synthesis and enhanced electrochemical activity for oxygen evolution reaction. Sci China Mater, 2017, 60: 119-130

37 Duan J, Chen S, Zhao C. Ultrathin metal-organic framework array for efficient electrocatalytic water splitting. Nat Commun, 2017, 8: 15341

38 Shen JQ, Liao PQ, Zhou DD, et al. Modular and stepwise synthesis of a hybrid metal-organic framework for efficient electrocatalytic oxygen evolution. J Am Chem Soc, 2017, 139: 1778-1781

39 Lu JN, Liu J, Dong LZ, et al. Exploring the influence of halogen coordination effect of stable bimetallic MOFs on oxygen evolution reaction. Chem Eur J, 2019, 25: 15830-15836

40 Jiang J, Huang L, Liu X, et al. Bioinspired cobalt-citrate metalorganic framework as an efficient electrocatalyst for water oxidation. ACS Appl Mater Interfaces, 2017, 9: 7193-7201

41 Mao FF, Hu CL, $\mathrm{Xu} \mathrm{X}$, et al. $\mathrm{Bi}\left(\mathrm{IO}_{3}\right) \mathrm{F}_{2}$ : The first metal iodate fluoride with a very strong second harmonic generation effect. Angew Chem Int Ed, 2017, 56: 2151-2155

42 Peng Y, Li Y, Ban Y, et al. Metal-organic framework nanosheets as building blocks for molecular sieving membranes. Science, 2014, 346: 1356-1359

43 Zhong KL, Qian MY. A novel one-dimensional Co ${ }^{\text {II }}$ coordination polymer: catena-poly[[hexaaquacobalt(II)] [[diaquabis(sulfato-kO) cobalt(II)]- $\mu-4,4^{\prime}$-bipyridine- $\left.\mathrm{k}^{2} N: N^{\prime}\right] \quad$ [[triaqua(sulfato-kO)cobalt (II)]- $\mu-4,4^{\prime}-$ bipyridine- $\left.\left.{ }^{2} N: N^{\prime}\right]\right]$. Acta Crystlogr C Cryst Struct Commun, 2012, 68: m265-m268

$44 \mathrm{Ju} \mathrm{S}$, Liu Y, Chen $\mathrm{H}$, et al. In situ surface chemistry engineering of cobalt-sulfide nanosheets for improved oxygen evolution activity. ACS Appl Energy Mater, 2019, 2: 4439-4449

45 Wang X, Fang J, Liu X, et al. Converting biomass into efficient oxygen reduction reaction catalysts for proton exchange membrane fuel cells. Sci China Mater, 2020, 63: 524-532

46 Zhu R, Ding J, Xu Y, et al. $\pi$-Conjugated molecule boosts metalorganic frameworks as efficient oxygen evolution reaction catalysts. Small, 2018, 14: 1803576

47 Liu CS, Zhang ZH, Chen M, et al. Pore modulation of zirconiumorganic frameworks for high-efficiency detection of trace proteins. Chem Commun, 2017, 53: 3941-3944

48 Qiu B, Cai L, Wang Y, et al. Fabrication of nickel-cobalt bimetal phosphide nanocages for enhanced oxygen evolution catalysis. Adv 
Funct Mater, 2018, 28: 1706008

49 Staszak-Jirkovský J, Malliakas CD, Lopes PP, et al. Design of active and stable Co-Mo-S ${ }_{x}$ chalcogels as $\mathrm{pH}$-universal catalysts for the hydrogen evolution reaction. Nat Mater, 2016, 15: 197-203

50 Feng X, Xing W, Song L, et al. In situ synthesis of a $\mathrm{MoS}_{2} / \mathrm{CoOOH}$ hybrid by a facile wet chemical method and the catalytic oxidation of $\mathrm{CO}$ in epoxy resin during decomposition. J Mater Chem A, 2014, 2: 13299-13308

51 Zhang R, Russo PA, Buzanich AG, et al. Hybrid organic-inorganic transition-metal phosphonates as precursors for water oxidation electrocatalysts. Adv Funct Mater, 2017, 27: 1703158

52 Favaro M, Drisdell WS, Marcus MA, et al. An operando investigation of $(\mathrm{Ni}-\mathrm{Fe}-\mathrm{Co}-\mathrm{Ce}) \mathrm{O}_{x}$ system as highly efficient electrocatalyst for oxygen evolution reaction. ACS Catal, 2017, 7: $1248-1258$

Acknowledgements This work was supported by the National Natural Science Foundation of China (U1904215, 21671170 and 21875207), the Top-notch Academic Programs Project of Jiangsu Higher Education Institutions (TAPP), the Program for New Century Excellent Talents of the University in China (NCET-13-0645), the Six Talent Plan (2015XCL-030) and Qinglan Project. We also acknowledge the Priority Academic Program Development of Jiangsu Higher Education Institutions and the technical support we received from the Testing Center of Yangzhou University. We also acknowledge the support from the postdoctoral fund of Yangzhou University.

Author contributions Pang $\mathrm{H}$ designed this study and supervised the experimental work. Bai Y performed the synthesis and characterizations. Zhang G, Zheng S and Li Q performed the characterizations; Bai Y wrote the paper with support from Pang $\mathrm{H}$ and $\mathrm{Xu}$ Q. All authors contributed to the general discussion.

Conflict of interest The authors declare no conflict of interest.

Supplementary information Experimental details and supporting data are available in the online version of the paper.

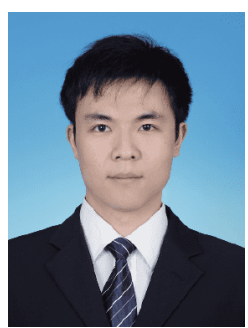

Yang Bai received his $\mathrm{PhD}$ degree in inorganic chemistry from Nanjing University. After working at the R\&D Department of Yangnong Chemical, he joined Prof. Huan Pang's group as a postdoctoral fellow in Yangzhou University. His research is focused on the functional nanomaterials for electrochemical applications.

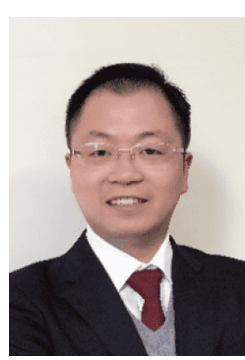

Huan Pang received his $\mathrm{PhD}$ degree from Nanjing University in 2011. He is now a university distinguished professor at Yangzhou University and Young Changjiang Scholars of the Ministry of Education. $\mathrm{He}$ is a member in the editorial board of FlatChem, young editorial board member of Chinese Journal of Inorganic Chemistry, and a managing editor of EnergyChem. His research interests include the development of inorganic nanostructures and their applications in nanoelectrochemistry focused on energy devices.

\section{吡啶调节2D双金属有机框架及其电催化析氧性能 研究}

柏杨 ${ }^{1}$, 张光勋 ${ }^{1}$, 郑莎莎 ${ }^{1}$, 李清 ${ }^{1,2}$, 庞欢 ${ }^{1 *}$, 徐强 ${ }^{1,3}$

摘要 二维金属有机骨架 $(2 \mathrm{D} \mathrm{MOF})$ 具有较大的比表面积和较高的 活性位点密度, 是改善电催化性能的理想载体. 通过简单的制备方 法获得 $2 \mathrm{D}$ 纳米结构受到了广泛的关注. 本文提出了一种吡啶调节 溶剂热合成方法, 用于合成镍/钴双金属MOF纳米片. 得到的MOF 材料具有矩形 $2 \mathrm{D}$ 形貌, 厚度约 20 纳米. 这些纳米片作为电催化剂在 碱性条件下表现出析氧反应(OER)活性. 其中, $\mathrm{Ni}_{0.5} \mathrm{Co}_{1.5}$-bpy $(\mathrm{PyM})$ 在 $1.0 \mathrm{~mol} \mathrm{~L}^{-1} \mathrm{KOH}$ 溶液中、电流密度 $10 \mathrm{~mA} \mathrm{~cm}^{-2}$ 时过电位低至

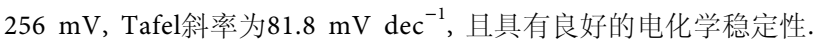
对催化反应后的电极材料研究表明, $\mathrm{Ni}_{0.5} \mathrm{Co}_{1.5}$-bpy (PyM)的高催化 活性来源于原位形成的活性氢氧化物和羟基氧化物. 该研究为 $2 \mathrm{D}$ MOF材料的可控合成及其与电催化性能构效关系的研究提供了理 论基础. 